\section{CINE Y 68: EL IMPACTO DE LA REVOLUCIÓN EN LA PANTALLA}

\author{
Josep Maria Caparrós Lera \\ Universidad de Barcelona \\ ORCID iD: https://orcid.org/0000-0001-8698-8037 \\ jmcaparros@ub.edu
}

Cómo citar este artículo/Citation: Caparrós Lera, J. M. (2018).

Cine y 68: el impacto de la revolución en la pantalla. Arbor, 194 (787): a431. https://doi.org/10.3989/arbor.2018.787n1004

Recibido: 31 enero 2017. Aceptado: 13 noviembre 2017.

RESUMEN: Se ofrece una panorámica histórica del cine realizado en torno al mayo de 1968, centrándose en el fenómeno militante en Francia y su repercusión en otros países. Desde la revolución de las nuevas olas europeas y mundiales hasta el nuevo cine latinoamericano, quedan sintetizados los principales grupos y autores. Asimismo, se constatan las películas más representativas -documentales y de ficción- realizadas durante y después de la revolución del 68 , haciendo hincapié en cinco filmes evocadores y en las contradicciones que se observan. Un apéndice reproduce el famoso Manifiesto por un cine militante de los Estados Generales.

PALABRAS CLAVE: Nouvelle vague; cine militante; Cahiers $d u$ Cinéma; Estados Generales del Cine Francés; Jean-Luc Godard; género político; telquelismo cinematográfico; serie Z; tercer cine.

\section{FILM AND '68: THE IMPACT OF THE REVOLUTION ON THE SCREEN}

Copyright: (C) 2018 CSIC. Este es un artículo de acceso abierto distribuido bajo los términos de la licencia de uso y distribución Creative Commons Reconocimiento 4.0 Internacional (CC BY 4.0).

ABSTRACT: A historical overview of films made around May 1968, focusing on the militant phenomenon in France and its impact on other countries is provided. Major groups and authors are synthesized from the European and world new wave until the New Latin American Cinema. Also, the most representative documentaries and fiction films made during and after the revolution of ' 68 , emphasizing five evocative movies and the contradictions observed therein. An appendix reproduces the famous Manifesto for militant cinema of the States General.

KEYWORDS: Nouvelle vague; militant film; Cahiers du Cinéma; States General French Film; Jean-Luc Godard; political gender; telquelismo film; series Z; third cinema. 


\section{INTRODUCCIÓN}

"El cine ha sido inventado por la burguesía para ocultar lo real a las masas"

(Jean-Luc Godard)

Desde la revolución de octubre de 1917, nunca un hecho revolucionario contemporáneo tuvo tanta repercusión en el séptimo arte. El mayo francés del 68 significó un antes y después en el medio cinematógrafo, tanto europeo como mundial.

La revolución de 1968, que traspasó las fronteras del país galo, fue preconizada por el fenómeno de las nuevas olas de los años sesenta, y no solo acabó con la nouvelle vague francesa sino que avanzaría otro tipo de cine, al tiempo que retrató unos acontecimientos históricos que posteriormente serían evocados en películas de ficción.

De todo ello, cronológicamente, vamos a tratar en este artículo, que hemos iniciado con una célebre frase de uno de los máximos representantes de esa ruptura estética y ética.

\section{Cahiers du Cinéma y la nouvelle vague}

Cuando en 1951, el gran teórico André Bazin fundó Cahiers du Cinéma difícilmente pensó en la renovación que significaría esta revista especializada, la cual promovió la política de autores y fue el trampolín de la nueva ola francesa, encabezada por François Truffaut, Claude Chabrol, Jean-Luc Godard, Jacques Rivette y el cerebro gris Éric Rohmer, junto al también innovador Alain Resnais -conocido como el "cineasta del tiempo"-, que estaba relacionado con la nouveau roman fundada por Robbe-Grillet (Chabrol y Godard, 1999; Douchet, 1998; Heredero y Monterde, 2002).

Esta nueva ola, que tendió a resaltar más la responsabilidad del director como autor de la obra cinematográfica, rompió las estructuras industriales en torno a la financiación de los filmes y dio "una relativa unidad temática en cuanto se centraba en un cine de personajes y de retratos humanos más que de grandes temas. Así el amor es su gran centro y a través de la juventud que lo vive se contemplan los problemas personales, humanos y sociológicos." (Hueso, 1983, p. 127).

Ciertamente, los componentes de la nouvelle vague realizaron un cine de tendencia psicológica, ofreciendo más retratos humanos - de la incertidumbre de unos tipos de hombre y mujer contemporáneos, muy parisienses- que temáticas concretas. Todo ello con un aire poco comprometido -al menos en apa- riencia-, sin crítica social ni política, y más sugeridor y amoral que pedagógico; pues las escenas de alcoba aparecieron en la pantalla sin ningún pudor.

Constantes de la nueva ola francesa serían los reducidos presupuestos económicos con los que trabajaban -intercambiándose a veces los puestos de trabajo dentro de la producción-, la referida ruptura con los viejos moldes y reglas al uso (como hicieron las vanguardias de los años veinte) y la improvisación y naturalidad narrativas. Con todo, una vez en rodaje, cada cineasta echó por su camino, constituyéndose años después -con estilo propioen autores de valía, que alcanzaron el reconocimiento mundial.

Y otro tanto podríamos decir de los diversos movimientos fílmicos europeos y mundiales de la década de los 60: free cinema inglés, nuovo cinema italiano, Junger Deutscher Film alemán, nuevo cine español, nuevas olas suiza, sueca y japonesa, cinema novo brasileño, o el denominado cine del deshielo de los países del este, por no ir más lejos.

Sin embargo, tras el mayo del 68, estas nuevas olas prácticamente se disgregaron y -centrándonos en Francia, objeto de nuestro estudio- la revista Cahiers du Cinéma, desaparecido también su impulsor (Bazin había fallecido en 1958), evolucionó hacia posturas ideológicas de extrema izquierda (Baecque, 1991). Y así, en octubre de 1969, elaboró un programa marxista, enfrentándose teóricamente con otra publicación nacida pocos meses antes -Cinéthique, los llamados "chicos terribles" de la teoría cinematográfica de ese período-y, a la vez, con La Nouvelle Critique, órgano del PCF, que operaba con cierta independencia del Partido Comunista. Tres revistas claves que entraron en polémica sobre la utilización del cine y la función de la cámara tomavistas tras la revolución de 1968 (Jelicié, 2016, pp. 7-41). Después Ilegaría Tel Quel, como más abajo comentaremos.

Pero si hubo un cineasta que anunció los hechos del mayo francés y el cine militante nacido en ese mismo período fue, sin duda, el mencionado Jean-Luc Godard (Liandrat-Guigues y Leutrat, 1995; Vianey, 1972); pues su película La chinoise (1967) divulgaba el pensamiento de un grupo maoísta y concluía con las palabras "fin d'un début", que eran premonitorias, ya que en la posterior obra de Godard se afirmaría la necesidad de politizar directamente la comunicación, dando a su estructura expresiva -la misma estructura dialéctica del análisis histórico materialista(Micciché, 1972, p. 163). 


\section{LA IRRUPCIÓN DE MAYO DEL 68}

Y así llegamos a la revolución francesa de 1968, desarrollada entre el 2 de mayo y el 23 de junio de ese año. Considerada por André Malraux -ex comunista y ministro de Cultura del presidente de Gaulle- como una película o un ensayo general para un film, el 68 fue, realmente, una generación de izquierdistas cinéfilos (Albiac, 1993, p. 97). De ahí que el propio Godard también manifestara: "El dolor que sufrimos permanece en el cine y, por tanto, en silencio".

Veamos, por tanto, cómo irrumpió en la pantalla, explicitándose en el ámbito francés, ahora que hemos llegado a su 50 aniversario.

Es obvio que los hechos de mayo causaron un gran impacto en el mundo cinematográfico, ya que dieron a luz una serie de grupos de realización de filmes, autores y colectivos militantes que hicieron del séptimo arte un instrumento para la lucha política (Beceyro, 1976; Zimmer, 1976).

\section{Loin du Vietnam}

Otra película antecedente y paralela a la citada cinta de Jean-Luc Godard fue la obra colectiva Loin du Vietnam (1967), realizada por siete cineastas de prestigio: Chris Marker, Joris Ivens, Agnès Varda, William Klein, Claude Lelouch y los ya referidos Resnais y Godard. Se trata de un documental dividido en episodios (110 minutos), donde no se indica quién dirige cada parte, en protesta contra la intervención militar norteamericana en la guerra del Vietnam, un conflicto bélico cuya denuncia está considerada como una de las semillas del mayo francés y de las manifestaciones en los Estados Unidos. Un film que constituyó un hito en el cine político, pues no solo apoyaba directamente a la resistencia comunista sino que atacaba al imperialismo estadounidense. Un año antes, uno de los autores de esta película, Joris Ivens, había dirigido otro documental, Le ciel, la terre, en el que daba "fe de la determinación inquebrantable de los norvietnamitas frente a los bombardeos aéreos casi cotidianos." (Véray, 2007, cit. por Cortés y Fernández-Savater, 2008, p. 55).

El documentalista Chris Marker, que no firma este film militante, fue el verdadero artífice de una obra "comprometida", en la cual colaboraron voluntariamente unos 150 técnicos. Rodada en Francia, Cuba y Bolivia, además de en Estados Unidos y Vietnam, su objetivo era que el público debatiera y se posicionase en contra de la guerra. Loin du Vietnam influyó en la creación de grupos y colectivos surgidos a partir de mayo del 68, ya que la mayoría de aquellos cineastas habían participado en esta experiencia.

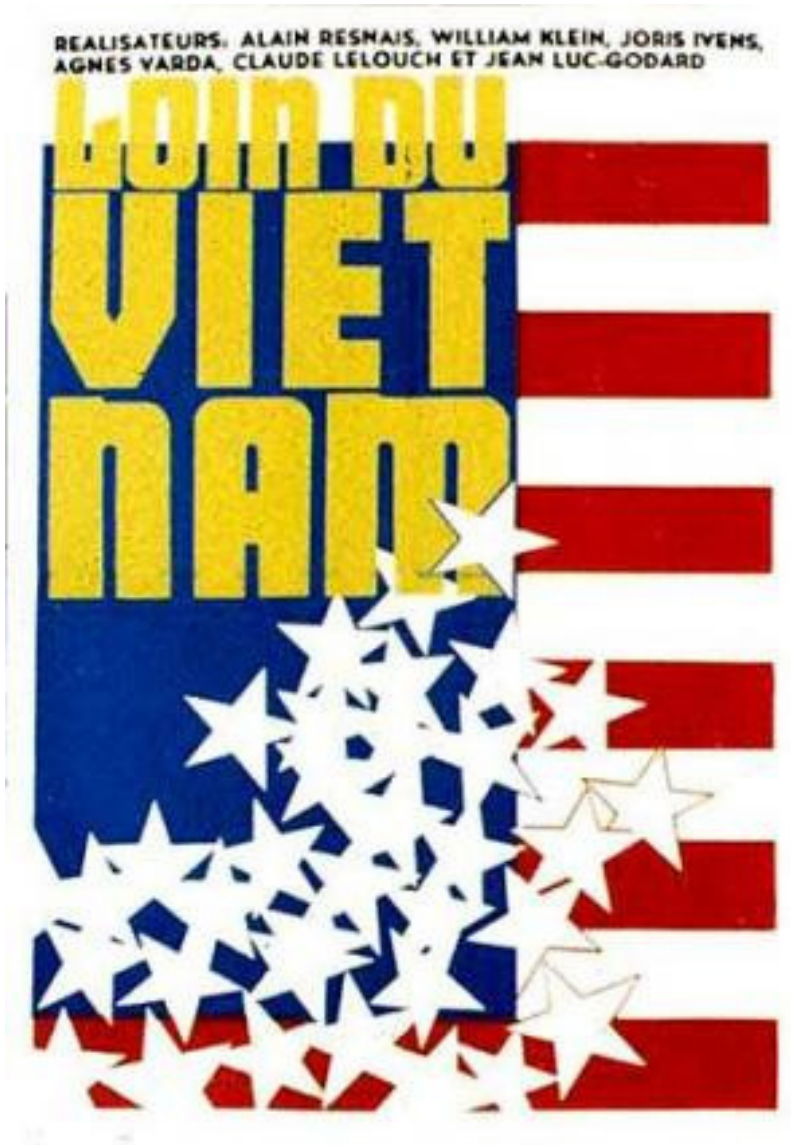

SLON y los grupos Medvedkin y Dynadia

En efecto, de Loin du Vietnam nació la Société pour le Lancement des Oeuvres Nouvelles (SLON), cooperativa independiente de producción que recuperaría el espíritu del frente popular de los años treinta y de la misma nouvelle vague (Marie, 1997). De ahí que Chris Marker estrenara en abril de 1968 À bientôt, j'espère, sobre una huelga obrera en una fábrica de Besançon, y también impulsase Le moindre geste (1968-1970), largometraje interpretado por niños con problemas psíquicos. Pero SLON, animada por el propio Marker, ofrecería sus servicios técnicos a otros colectivos de cine militante, como los famosos grupos Medvedkin y Dynadia.

Inspirado en el cine-tren de Aleksandr Medvedkin, que creó en 1932 un estudio fotográfico móvil instalado expresamente en unos vagones de tren que recorrían la Unión Soviética grabando películas y documentales que podían revelarse, montarse y exhibirse in situ, surgirían los grupos Medvedkin en Besançon y Souchaux, con cineastas-obreros militantes del sindicato CGT pero que actuaban como una "asociación libre". Sus realizaciones nacían de la iniciativa de uno 
de ellos, como respuesta ante un acontecimiento o un escándalo. Animados por Pol Cèbe, con la ayuda de SLON y del mismo Chris Marker, hasta 1974 dieron a luz títulos tan significativos como Classe de lutte, Avec la sang des autres, Images de la nouvelle société, Rhodia 4x8, Peugeot 11 juin 68, La traîneau-échelle, Lettre à mon ami Pol Cèbe, Les 3/4 de la vie, Week-end à Souchaux o Septembre chilien. Las obras de los Medvedkin han sido consideradas no tanto películas de propaganda como gritos de revuelta; restableciendo un vínculo con aquel cineasta soviético que manifestaba en sus cintas: "Camaradas, esto no puede seguir así!, ¡Camaradas, esto tiene que cambiar!”.

Mientras que el grupo Dynadia, organismo de propaganda audiovisual destinado a difundir las ideas políticas del PCF, realizaría numerosos filmes en 16 mm durante sus tres años de existencia (1968-1971), como Dix ans de gaullisme, Les immigrés en France, Le longement, Images sauvages y Les communistes dans la lutte, o el cortometraje Et maintenant?, que evoca los sucesos de mayo con imágenes de archivo y fotografías y posee una segunda parte sobre la campaña de Jacques Duclos, que fue el candidato comunista a las elecciones presidenciales de 1969.

\section{Grupo Dziga Vertov y otros colectivos}

Uno de los grandes pioneros de la escuela soviética de los años veinte, Dziga Vertov -autor del cine ojo y famoso también por sus noticiarios de actualidades y el documental El hombre de la cámara (1929)-, inspiró a Jean-Luc Godard y Jean-Pierre Gorin para formar un nuevo grupo militante (Font, 1976). El innovador Godard, de ideología ácrata, antiguo marxista-leninista y existencialista sartriano, en este período ya había abolido las reglas del lenguaje fílmico. Por eso, con el grupo Dziga Vertov se dedicó a un cine directamente político, dentro de la dialéctica materialista e incidiendo en el escándalo y la acción revolucionaria.

Fruto de su postura creadora, asociado con Gorin, Jean-Luc Godard dio a luz nueve películas radicales entre 1968 y 1972: Un film comme les autres, British sounds / See you at Mao, Pravda, Le vent d'est, Luttes en Italie, Jusqu'à la victoire (cinta inacabada sobre Al Fatah, rodada en Palestina, que terminará con su mujer, Ana-Marie Miéville, tras la disolución del grupo bajo el título Ici et ailleurs), Vladimir et Rosa, Tout va bien y Letter to Jane. Esta última realización con JeanPierre Gorin es un ensayo cinematográfico de 52 minutos, que deconstruye una sola fotografía de noticias de Jane Fonda en Vietnam.

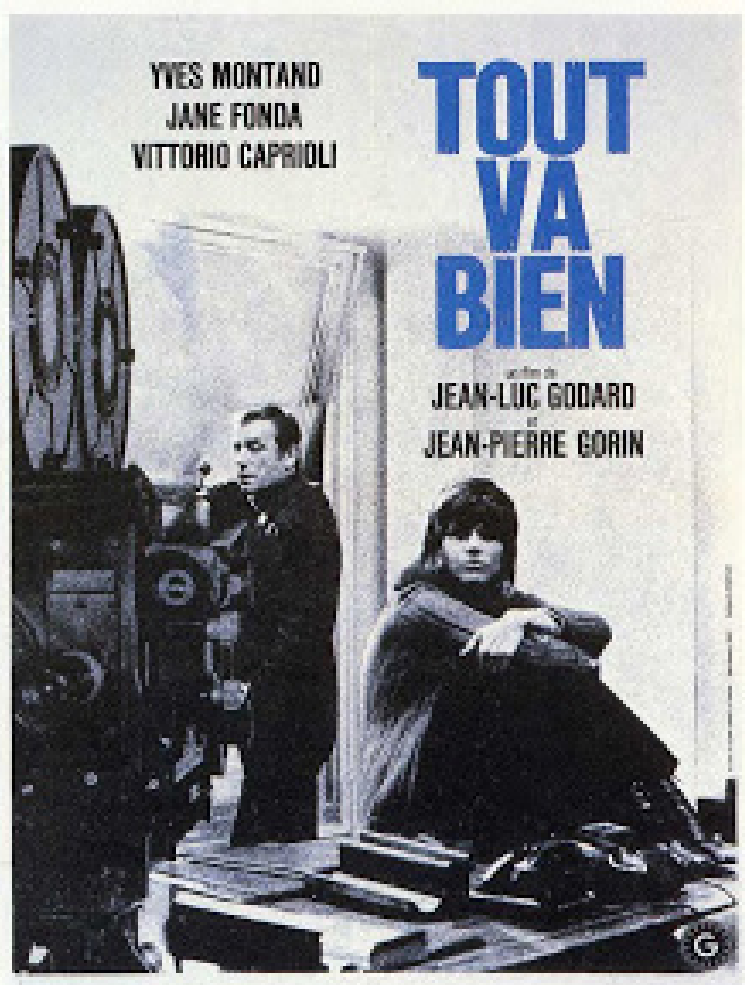

Con todo, en 1972 así definiría Godard su trabajo antisistema en el grupo Dziga Vertov: "Es un intento de romper con la habitual dictadura del director. De intentar relacionarse con la gente en una película sobre una base un poco más igualitaria que si sólo son considerados técnicos o esclavos. De intentar no establecer una jerarquía." (Goodwin y Marcus, 1972, p. 13).

En 1979, desengañado de los postulados del 68 y tras una etapa de experimentación en vídeo, Jean-Luc Godard volvería a su obra tradicional (Sauve qui peu / La vie), reflexionando sobre sus temas habituales y métodos deconstructivos de creación (Passion), al propio tiempo que evocaba con su película Nouvelle vague (1990) los principios de la nueva ola francesa, que él había ayudado a crear.

Asimismo, cabría mencionar aquí la labor análoga de sendos colectivos de cine militante aparecidos en ese período: Atelier de Recherche Cinémathographique (ARC), nacido a raíz de las primeras huelgas de ocupación en mayo del 68, con títulos como Le Droit à la parole, Oser lutter, oser voincre, CA13, comité d'action du 13ème arrondissement de Paris y Écute Joseph, nous sommes tous solidaires, que en el momento de su separación en 1969 contaba con una veintena de miembros; y Cinéastes Révolutionaires Proléteriens (CRP), 
surgido del ala izquierda de los Estados Generales del Cine, autores de películas como Flins 68-69 y Palestine vaincra, que fue el grupo que tuvo más problemas con las autoridades francesas; pues uno de sus componentes, Jacques Kébadian, sería condenado a prisión en 1970 (Pérez Turrent, 1972, p. 527). Después se sumarían otros colectivos, como los grupos Cinéma rouge, Vive la révolution ! (1968-1973), Prolétaire-Ligne Rouge o Cinéma Libre (1971-1974).

\section{ESTADOS GENERALES DEL CINEMA FRANCÉS (EGCF)}

No obstante, todo había comenzado el mes de febrero de 1968, cuando cientos de cineastas y críticos -a los que me sumé entonces con una carta dirigida al diario Le Monde-salieron en defensa del director de la Cinemateca Francesa, Henri Langrois, a quien el gobierno pretendía cesar. De Gaulle se propuso terminar con este espacio de debate donde se difundían las películas innovadoras de las nuevas olas de los 60. La respuesta fue contundente: se logró mantener a Langlois en su cargo y dejó preparado al mundo del cine para unirse a los sucesos revolucionarios. De ahí que se convocaran los antes citados Estados Generales del Cine a través de este llamamiento: "Ya sea usted técnico, intérprete, crítico o espectador, si quiere la REVOLUCIÓN, por, para y en el CINE, venga a militar a los ESTADOS GENERALES DEL CINEMA" (Bruck, 2017, 10 de mayo).

Enseguida se organizaron comisiones de trabajo con el propósito de elaborar una nueva concepción del cine, formando a la vez unidades de producción a fin de cubrir los eventos de la revolución. Y en medio de los enfrentamientos entre estudiantes y obreros con la policía, el 18 de mayo, por iniciativa de Godard y otros cineastas, también extranjeros, pidieron la suspensión del célebre Festival de Cannes, cosa que consiguieron con la dimisión del jurado internacional. Y el día 26 del mismo mes, los Estados Generales del Cinema Francés se reunieron en Suresnes; más de 1.300 personas deliberaron sobre los diferentes proyectos de reforma de la industria del séptimo arte.

\section{Manifiesto por un cine militante}

Entre el 17 y el 21 de mayo de 1968, el Comité Revolucionario de Cine-Televisión, los Sindicatos de Técnicos de la Producción Cinematográfica (CGT) y el Comité Conjunto Cine-Interfacultades hicieron "tres llamamientos" y, después de diversos proyectos para la transformación de las estructuras del séptimo arte, que fueron debatidos, publicaron un manifiesto por un cine militante de los Estados Generales. (Por su im- portancia y clara significación, para no romper el relato, lo reproducimos completo en el Apéndice).

Asimismo, hubo una moción final -más centrada en el cine francés-, que decía así:

"Los Estados Generales del Cine han nacido de un movimiento popular de contestación y lucha contra el orden económico, social e ideológico vigentes, el del capital protegido por el aparato del Estado. Los Estados Generales tienen como objetivo el hacer de la vida cultural, y por tanto del cine algo esencial a la vida de la nación, un servicio público.

1) Destrucción de los monopolios, la creación de un organismo nacional y único de distribución y exhibición de los films.

2) La autogestión contra la burocracia. Responsables elegidos por un tiempo límite, controlados y revocables.

3) Creación de grupos de producción autogestionados, que no estén sometidos a la ley capitalista del beneficio.

4) Abolición de la censura.

5) Autogestión para los estudiantes y los enseñantes, apertura hacia todas las clases sociales.

6) Unión estrecha del cine con una televisión autogestionada e independiente del poder y del dinero." (Pérez Perucha, 1988, p. 245).

Aparte de elaborar estos proyectos -algunos fueron propuestas de los ya mencionados Claude Chabrol, Jacques Rivette y Alain Resnais, junto a Jean-Louis Comolli y Louis Malle, entre otros cineastas galos-, los EFCF rodaron 70.000 metros de película en dos meses y más de treinta filmes en 16 y $35 \mathrm{~mm}$, con el objetivo de informar sobre las acciones del movimiento obrero y estudiantil. Al disolverse, los EGCF dieron paso a la formación de diversos colectivos de cine militante, cuyos principales grupos han sido comentados anteriormente.

\section{FILMES COETÁNEOS}

Aparte de algunos títulos antes citados y de los famosos cinétracts (brevísimos cortos documentales mudos, con fotografías y sin acreditar), se realizaron diversas películas contemporáneas a los hechos del mayo francés. Cortometrajes coetáneos como Le soulèvement de la jeunesse en mai 68, de Maurice Lemaître, La révolution n'est qu-un début. Continuons le combat, de Pierre Clémenti, Trente-trois jours en mai, de François Chardeaux, La reprise du 
travail aux usines Wonder, de Jacques Willemont, o el largo de Paul Seban, La CGT en mai-juin 1968. Obviamente, en esas jornadas "el cine se polarizó hacia el acontecimiento en acto, hacia el acontecimiento histórico vivido, y la actitud del creador se ajusta a ello." (Marsolais, 1974, pp. 331-332).

Asimismo, varias imágenes rodadas por los referidos grupos militantes fueron después vendidas y utilizadas para filmes de montajes posteriores, como Mai 68 (1974), de Gudie Lawaetz. Pero más importante sería el largometraje Grands soirs et petits matins. Extraits d'un film qui aurait dû exister (1978), de William Klein.

Rodado en $16 \mathrm{~mm}$ en los meses de mayo-junio de 1968 , sería estrenado ese mismo año en salas no comerciales y en las universidades francesas. Diez años después de que, a instancias de los EGCF, se hubieran captado con la cámara al hombro los sucesos más relevantes que tuvieron lugar durante esas jornadas en el barrio latino, el fotógrafo y cineasta estadounidense William Klein -autor de la sátira vanguardista Qui êtes-vous, Polly Maggoo? (1966)- montaría con su metraje original un documental (98 minutos) que mostraba con extraordinaria intensidad la atmósfera de las manifestaciones, reuniones y debates públicos. Una larga selección de imágenes, donde se evidencia que las calles de París en aquellos días habían pertenecido a los estudiantes, trabajadores, escritores... En este film testimonial, aparece repetidamente uno de los líderes la revolución, Daniel Cohn-Bendit, y las reacciones de los revolucionarios ante el discurso del presidente de Gaulle por televisión.

También cabe subrayar la importancia de otras películas que rememoran los hechos del mayo francés: Le fond de l'air est rouge (1977), de Chris Marker; Mourir à trente ans (1982), de Romain Goupil, y Reprise (1996), de Hervé Le Roux. Este último documental (180 minutos) es un film de reconstrucción histórica que trata de una huelga en una fábrica de provincias durante esos días de mayo, y pone el acento en las peleas encarnizadas entre los obreros comunistas y los maoístas, desestimando la influencia de la izquierda antiautoritaria (Porton, 2001, p. 108). Aun así, “apoyando su reflexión en la mirada de testigos implicados en el acontecimiento que relatan viviéndolo, los cineastas evitan la interpretación normativa del documental de montaje." (Biet y Neveux, 2007, cit. por Cortés y Fernández-Savater, 2008, p. 44).

Con todo, el "espíritu del 68" influyó en obras experimentales posteriores, aunque no trataran

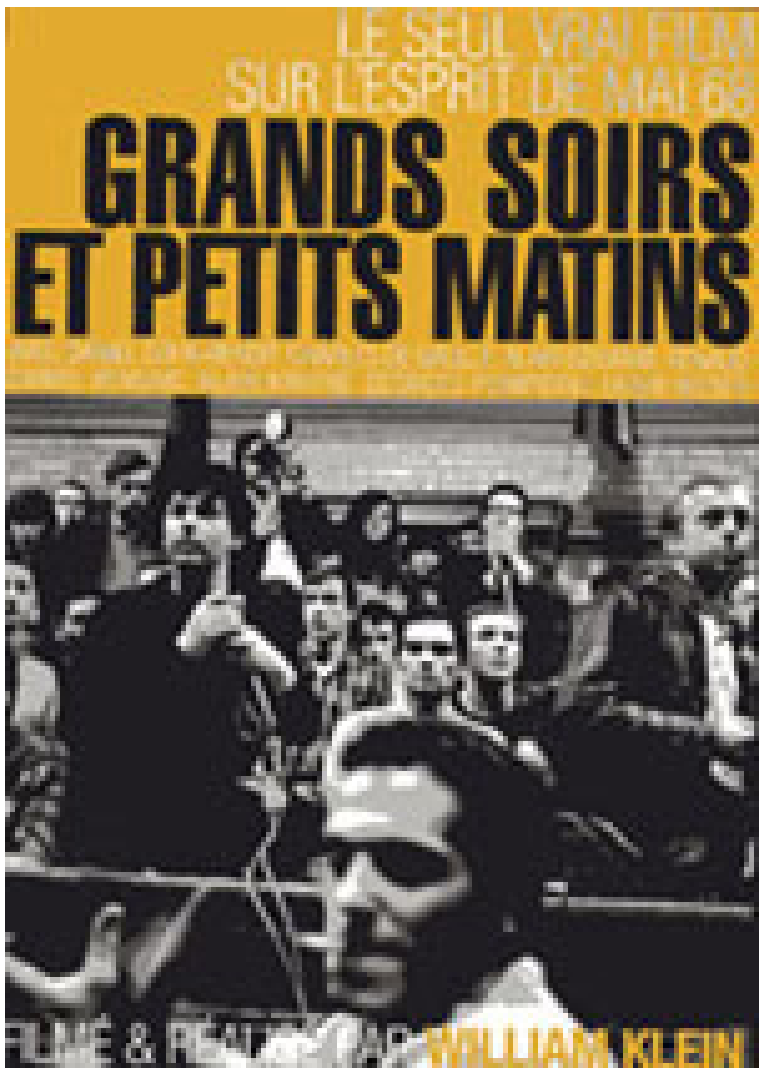

de los hechos de mayo. Películas de ficción tan dispares como la discutida L'An 01 (1973), de Jacques Doillon -con la colaboración de Alain Resnais y Jean Rouch-, una comedia acerca del intento de construir una nueva sociedad francesa basada en otros valores; la radical Winstanley (1975), de Kevin Brownlow y Andrew Mollo, sobre un episodio de la revolución inglesa del siglo XVII; y La celicia (1975), de Jean-Louis Comolli -redactor jefe de Cahiers de Cinéma entre 1966 y 1978-, en torno a una comuna de anarquistas italianos que a finales del siglo XIX se instalaron en Brasil, en una tierra cedida por el emperador Pedro II (1825-1891).

Pero esa realidad histórica es interpretada por Comolli desde una perspectiva crítico-ideológica post68. De ahí que afirmara: "Quise hacer un film histórico, pero con esta precisión: no he querido hacer un film sobre la historia como sucedió, sino sobre la historia como presente; es decir, pensar la historia como un terreno de contradicciones, de luchas, en el que la misma memoria participa de estas luchas, una historia siempre viva en nosotros". Realizada en color, con actores poco profesionales y en sistema de cooperativa -en $16 \mathrm{~mm}$, luego sería ampliada a 35 
para su exhibición comercial y mundial-, logra una gran belleza plástica y fuerza dramática (Caparrós Lera, 1978, pp. 206-209).

En la misma línea de experimentación, cabe mencionar a Jonas, qui aura vingt-cinq ans en l'an 2000 (1976), dirigida por el suizo Alain Tanner, dentro de los esquemas críticos de la posrevolución de mayo. Dejemos que el propio autor exponga su voluntad de expresión y describa la herencia del mayo francés:

En el espíritu de muchos, el 68 era un fenómeno político, en el sentido de la política politiquera. Los que militaban en un partido de esta época, como el personaje de Max en la película, creían en un cambio bastante radical en las instituciones. Su esperanza fue decepcionada y se produjo un gran vacío, que se vive aún hoy y que constituye una gran desilusión. Lo que me interesa es lo que queda, puesto que ciertas compuertas fueron abiertas, en un nivel discursivo, en un nivel de acciones individuales o en grupo que no estaban insertas en un partido. La manera como las mujeres o los jóvenes hablan hoy no es en absoluto la misma que antes del 68 ( ) El año 2000 puede ser el horror; el futuro de esos ocho personajes, que son el niño del final, su hijo, es quizás esta civilización. Pero no pidamos solamente a ese niño, Jonás [clara referencia al profeta bíblico], el diferir las esperanzas y echarlas sobre sí mismo. El film lo dice claro: tengamos cuidado. Si nosotros, ahora - profetiza Tannerno intentamos movernos un poco, él, dentro de 25 años, estará verdaderamente en la m...

Así, a finales del milenio, Alain Tanner realizaría la continuación de su profecía: Jonas et Lila, à demain (1999), sobre la vida de este personaje, un joven que acaba de terminar sus estudios de cine y que comparte su vida con una chica negra llamada Lila. Esta película viene a ser un retrato de los hijos de la generación del 68.

\section{PELÍCULAS EVOCADORAS}

$Y$ ya llegamos a las visiones más actuales, aquellos filmes que han evocado en el presente siglo el mayo francés. Pero hay un antecedente importante, que también debemos comentar.

Se trata de Milou en mai (1990), de Louis Malle. Este antiguo cineasta de los años de la nouvelle vague -pues trabajó paralelamente a la nueva ola francesa-, que participó activamente en los EGCF y estaba entonces un tanto desarraigado, regresó a su país para brindarnos una ácida visión de mayo del 68 . Narra el drama íntimo de una familia de la campiña francesa, que se reúne en su casa patriarcal ante la muerte de la madre de Milou -de cuerpo presente-, en espera de repartirse la herencia. Mientras, estalla la revolución de 1968, que ellos viven a través de la radio sin integrarse.

Con todo, Louis Malle no consideraba la película explícitamente dedicada a ese hecho histórico: "Es tan solo una comedia en la campiña francesa que se sitúa en esta época: el 68 no es más que el telón de fondo, el background de toda la acción". Bien interpretado y concebido con un estilo coral, lo más interesante de este film es el retrato que ofrece de ciertas mentalidades, especialmente de la burguesía gala, y su aguda reflexión crítica sobre la oposición campo-ciudad.

Por otra parte, Milou en mai es una crónica contextual, donde priva la ironía sobre la historia concreta, y en la cual no se escatiman concesiones exhibicionistas en torno a la liberación sexual, a la vez que rompe una lanza en favor del ecologismo; temas que se propulsaron en mayo del 68. Obra, por tanto, intelectual y minoritaria, que ha sido valorada así en una reciente comunicación (Bausero y Ventura, 2017):

Milou en mai es una película centrífuga. Los personajes son catapultados desde el interior de una casa de campo (de arquitectura tradicional y atiborrada de objetos) hacia el exterior en un doble movimiento que termina enclaustrado en una caverna prehistórica. Los sucesivos cortes de luz que se producen en la casa (con su correspondiente estética "en sombras") funcionan como dispositivo disparador de ese lanzamiento, el cual, a su vez, es modulado por la huidaregreso del representante máximo del orden establecido: Charles de Gaulle.

The Dreamers (2003), de Bernardo Bertolucci, es el siguiente film argumental que hay que comentar.

Discípulo de Pier Paolo Pasolini, Bertolucci había preconizado el mayo del 68 con Prima della rivoluzione (1964). Cuarenta años después, tras su criticado Novecento (1976), vuelve al "compromiso" político con una película evocadora de aquellos acontecimientos históricos.

Ambientada en los sucesos del París de 1968, Soñadores relata la historia de Matthew, un estudiante estadounidense que entabla relaciones con Isabelle y Theo, dos hermanos que asisten con frecuencia a la Cinémathèque. Cuando allí se realiza una manifestación relacionada con el mayo francés, Matthew es invitado a dejar su hotel y vivir con los hermanos, pues sus padres les han dejado solos en casa. Enseguida 
conoce que los hermanos son siameses y poseen una singular relación fraterna. Matthew comparte con ellos su afición por el séptimo arte y juntos recrean secuencias de filmes famosos, al tiempo que discuten ideas sociopolíticas y culturales, que evidencian opiniones antagónicas. A través de esas recreaciones, Isabelle y Matthew establecen una relación sentimental, que choca con los singulares lazos de ella con Theo. Matthew acaba implicándose en una violenta manifestación de protesta, y tomará conciencia de que sus ideales políticos y el comportamiento psicológico de los hermanos no concuerdan. Termina su relación con Isabelle, que decide seguir a su hermano, y abandona París.

Realizada en la línea erótica e incestuosa de otras películas escandalosas del mismo autor (El último tango en París, La luna), Bernardo Bertolucci combina el documental reconstruido con la ficción. Asimismo, durante el desarrollo del film se ven escenas de diferentes películas clásicas que se alternan con los acontecimientos de la narración. La mayoría de los veintitrés títulos que intercala "que van desde The Cameraman, de Buster Keaton, a Persona, de Ingmar Bergman, o Mouchette, de Robert Bresson, pasando por cuatro cintas de Godard, así como una banda sonora de veinte canciones célebres" tiene que ver con el juego de adivinar la película que hacen los protagonistas.

Obra, pues, de un cinéfilo y ensayo posmoderno, que también sería valorada en estos términos por los antes citados Cristina Bausero y Alejandro Ventura: "The Dreamers es un film centrípeto: los tres jóvenes encerrados en ese apartamento parisino (cuyo sentido vital se reduce al "puro sexo") son una muestra condensada de la multitud anónima que se manifiesta en las calles. En este caso, el deterioro escenográfico del interior representado por el caos y la acumulación de basurafunciona como metáfora del propio conflicto interior de esos jóvenes atrapados en un espacio laberíntico de impronta haussmaniana." (Se refieren al barón Georges-Eugène Haussman, que hizo una renovación urbanística en París en tiempos de Napoleón III).

Les amants réguliers (2003), de Philippe Garrel, es el siguiente film directamente evocador. Cuenta la historia de un joven poeta, François, que participa en la revolución de mayo francés. Allí conoce a Lilie. Y se inicia una pasión intensa que les hará revivir la ilusión tras el desencanto de la revolución perdida.

En Los amantes habituales, un grupo de jóvenes cultivan poesía, pintura y escultura, más droga y sexo, mientras ven cómo el nuevo mundo que querían construir va desapareciendo paulatinamente.
Nés en 1968 (2008), de Olivier Ducastel y Jacques Martineu, continúa en la misma línea evocadora, creativa y argumental. La acción se sitúa en la revolución estudiantil del 68. Tres amigos, Catherine, Yves y Hervé, animados por un compañero que ha estado en Berkeley, organizan una comuna en una vieja granja para intentar vivir con este dogma: "Igualdad entre hombres y mujeres, sin tabúes y sin ninguna otra regla". Pero, cuando salen al mundo exterior, topan con gobiernos de derechas, que les pueden llevar a la prisión. Los nacimientos que se producen en esa comuna dan lugar a una segunda generación en la que hay dos hijos gays, que se convertirán en miembros de la nueva revolución sexual.

Après mai (2012), de Olivier Assayas, cierra de momento el ciclo de películas evocadoras. Este film arranca en el París de principios de los setenta. Narra la vida de un estudiante de 18 años, Gilles, implicado por los cambios del mayo francés. Y como otros universitarios, duda optar entre radicalismo y sus proyectos más personales. En Después de mayo, las relaciones amorosas y los hallazgos artísticos llevan a Gilles y a sus amigos hasta Italia y Londres. A través de este itinerario existencial se sienten obligados a comprometerse con el propósito de hallar su espacio en esos años revolucionarios.

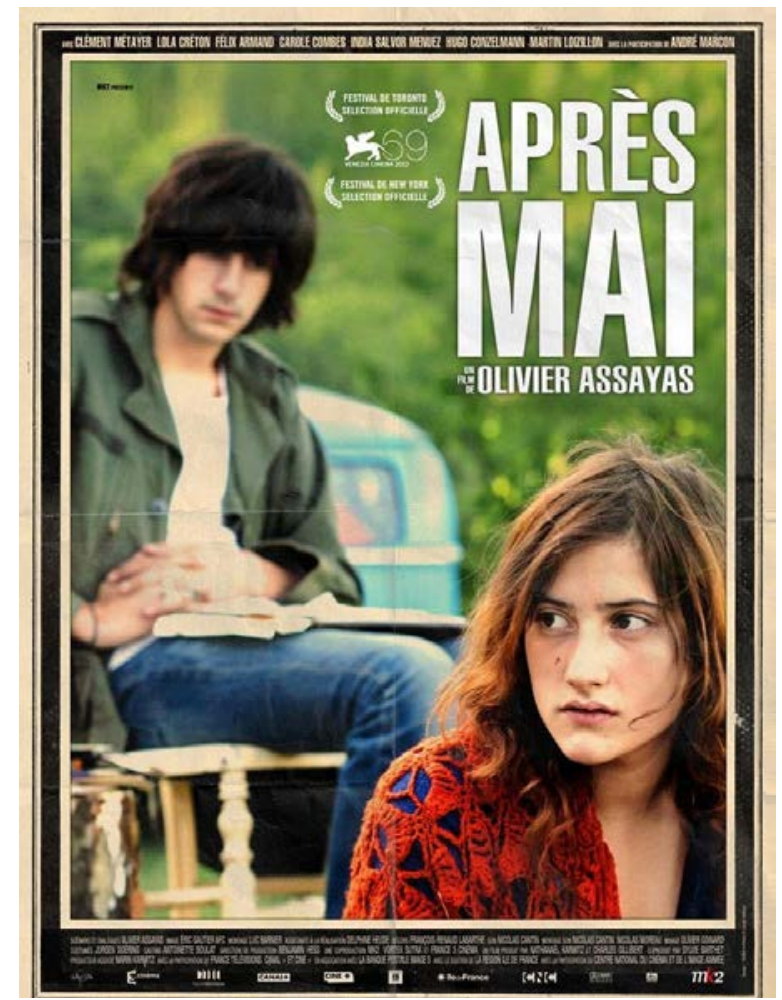


A estas cinco películas argumentales cabría aplicarles el juicio crítico de tres especialistas: David Cortés, comisario de una importante exposición sobre el mayo del 68, celebrada en 2008; y los profesores Juan Orellana y Jorge Martínez Lucena, quienes se referirán a la influencia de los filósofos Herbert Marcuse (Eros y civilización), Gilles Lipovetsky (La felicidad paradójica) y Charles Taylor (La ética de la autenticidad):

El cine realizado en mayo del 68 incorporó muchas de las cuestiones abiertas en el acontecimiento y lo pone en relación con aquellas aproximaciones cinematográficas posteriores (...), donde mayo del 68 aparece reinscrito en un conjunto de estereotipos, reduciéndolo al tópico de las barricadas estudiantiles parisinas y expurgándolo de toda conflictividad política al plantearlo exclusivamente como un movimiento juvenil de liberalización de las costumbres (Cortés, 2016).

El "individualismo" del que habla Taylor es la característica principal de los personajes de estos filmes, personajes que, sucumbiendo a la dictadura de los deseos, buscando el lastimoso bienestar nietzscheano, acaban cayendo en una profunda infelicidad (Orellana y Martínez Lucena, 2009).

\section{LA HERENCIA CINEMATOGRÁFICA DEL MAYO FRANCÉS}

Dos países heredaron enseguida la experiencia del mayo francés: Estados Unidos e Italia.

Por un lado, el cine "contestatario" norteamericano de finales de los años sesenta y principios de los setenta, de manos de Denis Hopper (Easy rider), Arthur Penn (Alice's restaurant) y Robert Altman (M.A.S.H.), junto al documental Woodstock (Michael Wadleigh, 1970), sobre el legendario festival de música rock. Fue un grupo de cineastas que puso en la picota el American way of life -como antes lo había hecho el fenómeno underground estadounidense, el director independiente Robert Kramer o los coetáneos Newsreel de Nueva York y San Francisco, que tenían como finalidad realizar películas sobre y para "la nueva izquierda"-, pero que finalmente sería asimilado por la industria de Hollywood (Biskind, 2004).

Y por otro, el cine político italiano, encabezado por Marco Bellocchio -siguiendo el ejemplo de Cannes, también se interrumpió ese año el Festival de Pesaro-, que se inicia con la formación de diversos colectivos de filmes militantes en Turín, Roma y Milán. Son célebres los cinegionale rodados por los grupos del movimiento estudiantil italiano, aunque no poseían -según el crítico Pio Baldelli, en su ponencia El cine político y el mito de las superestructuras (1968)- informaciones precisas sobre los problemas reales, sino que intentaban provocar mítines políticos de adhesión estática, no de acción, y rendir homenajes a los "héroes" de las guerrillas y lograr una contemplación fervorosa en asambleas y manifestaciones (Baldelli et al., 1970). Y este teórico destacó como un claro ejemplo de cine militante Apollon, una fabrica occupata, film realizado por el Centro de cinediarios libres de Roma, con un coste de 700.000 liras, 5.000 metros de película en $16 \mathrm{~mm}$ y de una hora de duración; producto que calificaría de paternalista, falseador (trata de una huelga de 320 obreros tipógrafos), tanto en el plano informativo como en el lenguaje. Los obrerosvíctimas -comenta este crítico de la "vieja guardia" del PCl- se interpretan a sí mismos, se representan, pues la acción gira en torno a dos protagonistas que en el fondo exaltaban el poder constituido. Todo estaba retóricamente calculado, slogans contradictorios incluidos (Caparrós Lera, 2003, pp. 214-216).

Asimismo, llegarían las películas del llamado realismo crítico italiano -pero desde una perspectiva eurocomunista de influencia gramsciana-, con Francesco Rosi, Bernardo Bertolucci, Elio Petri, Francesco Rosi, Damiano Damiani y Giuliano Montaldo a la cabeza, y títulos tan representativos como La estrategia de la araña (1970), de Bertolucci; Investigación sobre un ciudadano libre de toda sospecha (1970) y La clase obrera va al paraíso (1972), de Petri; II caso Mattei (1972) y Lucky Luciano (1973), de Rosi; Confesiones de un comisario (1971), de Damiani; y Sacco e Vanzetti (1971), de Giuliano Montaldo, por no citar más. Género político, que sería asimilado comercialmente, del cual es pionero Costa-Gavras, con la "oscarizada" $Z$, en 1969, y La confesión, en 1970. Cineasta que muchos años después haría una referencia en su película $L a$ petite apocalypse (1993), una comedia que satiriza a los ex intelectuales de mayo del 68, inspirada en la novela homónima del polaco Tadeusz Konwicki.

Todo ello daría lugar al denominado cine de la serie $Z$-cineastas que, adaptándose al estilo thriller norteamericano, defendían que las formas de expresión son neutras y deben ponerse al servicio de un contenido político de izquierda- y también a sus antagonistas de la citada revista de teoría y crítica literaria Tel Quel -entre sus colaboradores figuraban Roland Barthes, Jacques Derrida, Umberto Eco y Michel Foucault-, que optaba por el ultraizquierdismo intelectualista y estético, además del llamado telquelismo cinematográfico (Asensi Pérez, 2006). Manifestaban que el arte fílmico estaba viciado por 
su nacimiento en un contexto capitalista y burgués y que era necesario revolucionar las formas antes de ocuparse del contenido.

“Un tiempo precioso se perdió durante los años que siguieron al mayo del 68 en la elaboración de una est-ética que se ha revelado en última instancia ultra-izquierdista. Ciertamente, la búsqueda de un "cinema materialista" no estaba desprovista de valor. El telquelismo cinematográfico ha tenido el mérito de denunciar la función opiomática del cinema tradicional (...) Se ha confundido cinema y cinema hollywoodense, proclamando que el séptimo arte estaba congénitamente enfermo de peste" (Hennebelle, 1977, II, p. 463). Y cita a Jean-Patrick Lebel, quien afirma que "la cámara no segregaba la ideología como el hígado segrega la bilis" (Lebel, 1973). Concluye así su discurso Guy Hennebelle: "Esta epidemia (cuyo contagio se ha hecho sentir en varios países extranjeros) ha retrasado sin duda el advenimiento de una vanguardia política en el ámbito del cinema francés."

Por su parte, el historiador Jean-Pierre Jeancolas hablaba de tres tendencias políticas fundamentales en el film francés post-68: un cine de la liga de los derechos del hombre -donde destacaría Elise ou la vraie vie, de Michel Drach, y El atentado, de Yves Boisset, sobre el caso Ben Barka-; un cine del programa común de la izquierda -con Beau Masque, de Bernard Paul, o Nada, de Claude Chabrol, más próxima a las tesis del PCl-, y más allá... del cine gauchiste -con La femme de Jean, de Yannick Bellon, y On s'ent trompé d'histoire d'amour, de Jean-Louis Bertucelli y Colline Serraux, en la línea feminista y descolonizadora (Jeancolas, 1974, cit. por Hennebelle, 1977, I, pp. 150-159).

Ciertamente, desde fines de los sesenta y durante toda la década siguiente, se consolidaría un nuevo cine militante más allá de ámbito francés. Las producciones de Fernando E. Solanas y Octavio Getino -famosos por La hora de los hornos (1968)- y el Cine Liberación, junto a las del grupo Cine de la Base de Raymundo Gleyzer-desaparecido durante la dictadura militar argentina-, consiguen reconocimiento mundial y una gran difusión.

Este movimiento "revolucionario", aparte del referido cinema novo brasileño (Glauber Rocha), se extenderá a la Cuba de Castro (Tomás Gutiérrez Alea), Bolivia (Jorge Sanjinés), Chile (Patricio Guzmán, Miguel Littin), Colombia, México, Uruguay y Venezuela, donde se realizarán experiencias análogas (Mestman, 2016). Se trata del llamado tercer cine, que se planteaba también como una batalla política contra las concepciones burguesas del séptimo arte, como "una lucha política en la cultura formando parte de la lucha política en genera" (Pérez Turrent, 1972, p. 514).

O sea que, con sus valores y defectos, la sombra de mayo del 68 es alargada.

\section{A MODO DE CONCLUSIÓN}

De nuevo citamos al historiador Ángel Luis Hueso, en su síntesis sobre la revolución de 1968:

La gran aportación del cine surgido en este momento fue poner en evidencia la necesidad de que la imagen adoptara una postura más crítica ante situaciones políticas vividas por la sociedad; no podemos olvidar, además, que en estos mismos años cinematografías con tanta fuerza como la estadounidense o la italiana van a reflejar una fuerte preocupación por las transformaciones políticas que experimentan sus propios países (Hueso, 1998, p. 124).

Es indiscutible, pues, la importancia del séptimo arte entre los protagonistas del mayo francés. Reproducimos, finalmente, lo que afirma el historiador y sociólogo Juan María Sánchez-Prieto, en su resumen de esta utópica revolución:

El cine ha sido el reino de este mundo para una generación. Un mundo más real que el discurso de los políticos, que la crítica de la oposición. La ficción del cine se antojaba terriblemente verdadera. El ojo del cine -había sentado Morin- eleva lo real a irreal, el presente a lo vivido, el recuerdo y el sueño, a un mismo nivel, el nivel del imaginario, tan mitómano como lúcido. El cine fue un consuelo mayor, a la espera de la revolución (Sánchez-Prieto, 2001, p. 127).

En definitiva, pienso que las películas realizadas en torno y sobre el mayo del 68 no pasarán con letras de oro a la historia del cine. Pero hoy, con motivo del 50 aniversario, destacan como un fenómeno creativo y testimonial que valía la pena constatar.

\section{AGRADECIMIENTOS}

A la documentalista e historiadora Violeta Bruck, que sintetizó este tema en un ensayo en línea, que coincide con algunos de los conceptos y apreciaciones que personalmente ya tenía en mente antes de consultarlo y escribir este artículo.

El presente trabajo se encuentra vinculado al Proyecto I+D "Excelencia" (2013-2016), titulado Modelos escenográficos en el cine histórico, concedido por el Ministerio de Economía y Competitividad. 


\section{BIBLIOGRAFÍA}

Albiac, G. (1993). Mayo del 68. Una educación sentimental. Madrid: Temas de Hoy.

Asensi Pérez, M. (2006). Los años salvajes de la teoría. Philippe Sollers, Tel Quel y la génesis del pensamiento post-estructural francés. Valencia: Tirant lo Blanch.

Baecque, A. de (1991). Cahiers du cinéma. Histoire d'une revue 2. Cinéma, tours détours 1959-1981. París: Cahiers du cinéma.

Baldelli, P. et al. (1970). Problemas del nuevo cine. Madrid: Alianza.

Bausero, C. y Ventura, A. (2017). El espacio interior como escenario histórico. Los casos de Milou en mai y The Dreamers en mayo del 68. En: Camarero Gómez, G. y Sánchez barba, F. (eds.) Actas del $\checkmark$ Congreso Internacional de Historia y Cine: Escenarios del cine histórico. Madrid: Universidad Carlos III, pp. 489-503.

Beceyro, R. (1976). Cine y política. Caracas: Dirección General de Cultura de la Gobernación del Distrito Federal.

Biet, Ch. y Neveux, O. (eds.) (2007). Une histoire du spectacle militant. Théâtre et cinéma militants 1966-1981. Montpellier: L’Entretemps.

Biskind, P. (2004). Moteros tranquilos, toros salvajes. La generación que cambió Hollywood. Barcelona: Anagrama.

Bruck, V. (2017, 10 de mayo). Estados Generales del Cine Francés: el cine en revolución. [En línea]. Disponible en: https://www.laizquierdadiario.com/ Estados-Generales-del-Cine-Frances-elcine-en-revolucion

Bulletin des États Généraux du Cinéma (1968), 1-3. París: Éditions du Terrain Vague.

Caparrós Lera, J. M. (1978). El cine político visto después del franquismo. Barcelona: Dopesa.

Caparrós Lera, J. M. (2003). Historia del cine europeo. De Lumière a Lars von Trier. Madrid: Rialp.
Chabrol, C. y Godard, J-L. (1999). La Nouvelle vague. París: Cahiers du cinéma.

Cortés, D. (2016). Mayo del 68 en el cine. En: Camarero Gómez, G. y Sánchez barba, F. (eds.) Actas del V Congreso Internacional de Historia y Cine: Escenarios del cine histórico. Madrid: Universidad Carlos III.

Cortés, D. y Fernández-Savater, A. (eds.) (2008). Con y contra el cine. En torno a mayo del 68. Barcelona-Madrid-Sevilla: Fundació Antoni Tàpies / Sociedad Estatal de Conmemoraciones Culturales / Universidad de Andalucía.

Douchet, J. (1998). Nouvelle vague. París: Cinémathèque Française / Hazan.

Font, R. (ed.) (1976). Jean-Luc Godard y el grupo Dziga Vertov: un nuevo cine político. Barcelona: Anagrama.

Goodwin, M. y Marcus, G. (1972). Doble Feature. New York: Outerbridge \& Lazard.

Hennebelle, G. (1977). Los cinemas nacionales contra el imperialismo de $\mathrm{Ho}$ llywood. Nuevas tendencias del cine mundial (1960-1975). Valencia: Fernando Torres.

Heredero, C. F. y Monterde, J. E. (eds.) (2002). En torno a la Nouvelle vague. Rupturas y horizontes de la modernidad. Valencia: Institut Valencià de Cinematografia Ricardo Muñoz Suay.

Hueso, A. L. (1983). El cine y la historia del siglo XX. Santiago de Compostela: Universidad de Santiago de Compostela.

Hueso, A. L. (1998). El cine y el siglo XX. Barcelona: Ariel.

Jeancolas, J-P. (1974). Le Cinéma des Françaises, 1969-1974. Les années Pompidou. Créteil: Maison des Arts et de la Culture.

Jelicié, E. (2016). Una controversia francesa. Cine y política después del 68: $\mathrm{Ca}$ hiers du cinéma, Cinéthique y La Nouvelle Critique (1969-1971). En: Comolli, J-L. et al. Mayo Francés. La cámara opaca. El debate cine e ideología. Buenos Aires: El cuenco de plata, pp. 7-41.
Lebel, J-P. (1973). Cine e ideología. Buenos Aires: Granica.

Liandrat-Guigues, S. y Leutrat, J.-L. (1995). Jean-Luc Godard. Madrid: Cátedra.

Marie, M. (1997). La Nouvelle vague. Une école artistique. París: Nathan.

Marsolais, G. (1974). L'aventure du cinéma direct. París: Seghers.

Mestman, M. (coord.) (2016). Las rupturas del 68 en el cine de América Latina. Buenos Aires-Madrid: Akal.

Micciché, L. (1972). II nuovo cinema degli anni '60. Torino: ERI.

Orellana, J. y Martínez Lucena, J. (2009). Apocalipsis narcisista y autenticidad en el cine posmoderno. Filmhistoria Online, 19 (2-3).

Pérez Perucha, J. (coord.) (1988). Los años que conmovieron al cinema. Las rupturas del 68. Valencia: Filmoteca de la Generalitat Valenciana.

Pérez Turrent, T. (1972). Puesta al día (1965-1971). En: Sadoul, G. Historia del cine mundial. Desde los orígenes hasta nuestros días. México-Madrid: Siglo XXI, pp. 495-566.

Porton, R. (2001). Cine y anarquismo. La utopía anarquista en imágenes. Barcelona: Gedisa.

Sánchez-Prieto, J. M. (2001). La historia imposible del mayo francés. Revista de Estudios Políticos, 112, pp. 109-133.

Véray, L. (2007). Loin du Vietnam (1967). Una concepción creativa y colectiva del cine político. En: Biet, Ch. y Neveux, O. (eds.) Une histoire du spectacle militant. Théâtre et cinéma militants 1966-1981. Montpellier: L'Entretemps.

Vianey, M. (1972). Esperando a Godard. Madrid: Fundamentos.

Zimmer, Ch. (1976). Cine y política. Salamanca: Sígueme. 


\section{APÉNDICE}

\section{MANIFIESTO POR UN CINE MILITANTE DE} LOS ESTADOS GENERALES

La dictadura burguesa actúa en todos los niveles. El cine y la televisión, a la vez industria y espectáculo, no son únicamente una fuente de ganancias para algunos, sino que constituyen también un arma ideológica en manos de la clase en el poder. Asimismo, por lo que respecta al cine, los capitalistas tienen en él, como en todas las ramas de la actividad social, uno de sus monopolios. Por esta razón han creado un sistema que se manifiesta como una coacción frente a los trabajadores de la profesión y como orientación ideológica para el público.

Este sistema trae consigo dos aspectos. Uno, represivo: censura gubernamental que acarrea a menudo la autocensura, y separaciones sociales, económicas e ideológicas en la producción y en la distribución. El otro, liberal, pero en realidad destinado a reforzar su dominio, mascarada de una pretendida Intelligentsia, flecos de estetas cortados de la realidad social.

Los festivales, que se vinculan con el aspecto liberal del sistema a causa de su máscara de efervescencia cultural son, de hecho, ferias comerciales. En cuanto a su pretendida significación cultural, esta se reduce, a causa del manejo de los premios y de las campañas de prensa, a intento de integración de obras que chocan momentáneamente con los valores admitidos.

Para llevar a cabo una ruptura ideológica con el cine burgués nos pronunciamos por la utilización de las películas como arma política.

¿Cómo puede ser una película un arma política?

Facilitando informaciones que la prensa burguesa escrita y hablada ignora deliberadamente (huelgas locales, despidos, lucha revolucionaria en cualquier país).

Ayudando a analizar los mecanismos del sistema capitalista con el fin de poner de relieve sus contradicciones y de ese modo ayudar a combatirlas.

Popularizando, comprendiendo y extrayendo enseñanzas de todas las formas de lucha revolucionaria, desempeñando en todos esos casos una función crítica y movilizadora.

En consecuencia, es necesario ligar, tanto como sea posible, y en función de las situaciones objetivas y de las posibilidades de acción que estas implican, esta ruptura ideológica a una práctica militante. Por eso defendemos:

1) La utilización del cine como arma de lucha política, tal y como se ha definido antes, y sobre el que los militantes implicados ejerzan un control político tanto en la realización como en su distribución.

2) La utilización del cine como base de intercambios de experiencias políticas; de ahí deriva la necesidad de suscitar tras cada proyección cualesquiera debates que puedan desencadenarse a consecuencia de los problemas concretos que la originaron.

3) La utilización y la realización de películas vinculadas a acciones políticas (mítines, manifestaciones, huelgas, etc.).

4) Paralelamente a la difusión de tales películas, una información que las explique, las complete o las provoque.

(Bulletin des États Généraux du Cinéma, 1, 1968). 